\title{
Making Family Planning Services Relevant to Adolescents: Perspectives from Rural Communities in Central Ghana
}

\author{
Yeetey Enuameh ${ }^{1,2 *}$, Charlotte Tawiah1, Samuel Afari-Asiedu1, Obed Ernest A. Nettey1,

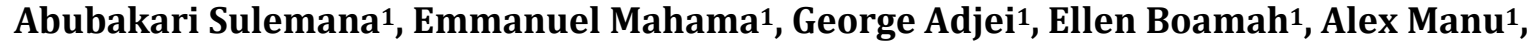 \\ Stephanie Gyaase', Charles Zandoh'1, Nelson Amanfo', Kwaku Poku Asante1, \\ Timothy Letsa ${ }^{3}$, Seth Owusu-Agyei ${ }^{1}$ \\ ${ }^{1}$ Kintampo Health Research Centre (KHRC), Kintampo, Ghana \\ ${ }^{2}$ Drexel University School of Public Health, Philadelphia, USA \\ ${ }^{3}$ Regional Health Directorate, Ghana Health Service, Sunyani, Ghana \\ Email: *yeetey@gmail.com
}

Received 18 September 2014; revised 21 October 2014; accepted 17 November 2014

Copyright (C) 2014 by authors and Scientific Research Publishing Inc.

This work is licensed under the Creative Commons Attribution International License (CC BY). http://creativecommons.org/licenses/by/4.0/

c) (i) Open Access

\section{Abstract}

In lower middle-income countries like Ghana, it is common to find low contraceptive use among adolescents with corresponding high pregnancy outcomes. Evidence points to the fact that the use of contraceptives prevents maternal, neonatal and infant deaths, but in most lower middle-income countries, socio-cultural practices inhibit adolescents' use. Ensuring the uptake of family planning among adolescents is deemed a necessary means of reducing maternal, neonatal and infant mortality. This manuscript seeks to provide contextually relevant approaches to satisfying family planning needs of adolescents in a population lacking it. We employed a qualitative study design from an interpretive paradigm with phenomenology as the methodology to understand societal attitudes towards family planning delivery to adolescents, so as to arrive at contextually appropriate ways of providing family planning to this needy group. Focused group discussions and in-depth interviews techniques were used in data collection among adolescents, relevant community opinion leaders and family planning $\&$ health services providers. Themes that emerged from data analysis with respect to "perspectives on family planning care delivery to adolescents" and "best ways in addressing adolescents' family planning needs" are presented, followed by discussion of the issues emerging. A significant and encouraging finding of the study was that opinion leaders and healthcare providers viewed family planning as a means of protecting adolescents against pregnancies and their complications. A key recommendation is for policy makers and political leaders to enact legislations that enable adolescents to have friendly family planning service delivery in all places and at all times.

"Corresponding author.

How to cite this paper: Enuameh, Y., et al. (2014) Making Family Planning Services Relevant to Adolescents: Perspectives from Rural Communities in Central Ghana. Open Journal of Preventive Medicine, 4, 852-859.

http://dx.doi.org/10.4236/ojpm.2014.411096 


\section{Keywords}

\section{Adolescents, Young People, Family Planning, Kintampo, Ghana}

\section{Introduction}

Contraceptive use is low, whereas pregnancy rates remain high among adolescents in lower middle income countries (LMICs) [1] [2]. Pregnancy rates among adolescents 15 to 19 years of age have remained high in Ghana in spite of a slight decline from 14\% in 2000 to $12.2 \%$ in 2007 [1]. Births to adolescents within the middle belt of Ghana, where this study was carried out also dropped slightly from $14.5 \%$ to $13.4 \%$ in the same time period [1]. Pregnancies and births to adolescents in the studied area (i.e. Kintampo north and south districts) were found to be higher than the national average [3]. Between 2005 and 2009, 10\% of all births within the Kintampo Health and Demographic Surveillance System (KHDSS), which covers the entire study area were to adolescent mothers [4].

Most pregnancies in adolescents are unplanned and often result in unsafe abortions; they are also associated with higher risks to both mother and her newborn [5]. Adolescents have maternal mortality ratios that are usually twice as high as those of women in their twenties [5]. Infant and child deaths are equally higher among those born to adolescent mothers compared to adult mothers [5] [6].

Though contraceptive use is known to prevent between 20 and 35 percent of maternal deaths in most lower and middle-income countries, socio-cultural practices limit access of adolescents to family planning (FP) [7]. According to the 2008 Ghana Demographic Health Survey (GDHS), knowledge of at least one type of contraceptive was generally low among adolescents aged 15 to 19 years [1]; the use of any contraceptive method was lowest in the 15 to 19 year olds, slightly higher in females (19.5\%) compared to males (14.7\%) [1]. Unmet need for FP is also far greater among adolescents 15 - 19 years (62\%) than women 30 - 34 years (33\%) [8]. FP prevalence among adolescents in Ghana however has been observed to have increased from 2003 to 2005, associated with a greater use of traditional as compared to modern FP methods [9]. Ensuring FP uptake by adolescents will lead to a reduction in maternal mortality (MDG 5) as well as infant mortality (MDG 4) in lower middle income countries [7]. Recent studies of adolescent sexual and reproductive health (ASRH) needs in the study area confirmed poor knowledge and use of contraceptive methods [3] [10].

The Kintampo Health Research Centre (KHRC) initiated a sexual and reproductive health (SRH) survey in 2011. This was part of a larger program to assess the SRH needs of KHRC's study communities to facilitate the development of innovative interventions to benefit populations in Ghana and beyond. The main objective of the current study was to identify contextually relevant and best approaches to satisfying the FP needs of adolescent populations in the middle part of Ghana. To address this objective we looked at how the community and healthcare providers perceived FP services to adolescents; and the views of adolescents and the communities in which they lived on the best ways based on their experiences to address adolescent FP needs.

\section{Methods}

We approached this work from an interpretive paradigm with phenomenology as the methodology in order to provide a deeper insight into contextual and societal factors that influence FP use by adolescents in the communities. This approach ensured an understanding of the community's and healthcare providers' attitudes to FP delivery to adolescents based on their experiences and perspectives. It helped further explain community reaction to the idea of providing adolescents with FP services and assessing contextually best and practical ways of meeting the FP needs of adolescents.

The Kintampo districts have a predominantly rural population and they occupy a surface area of $7162 \mathrm{~km}^{2}$ in the geographical center of Ghana [4]. The study population consisted of school going adolescents, opinion leaders (traditional rulers, political representatives, religious leaders, etc.) and health workers providing FP services in the communities. They were purposively sampled from both urban and rural communities of the Kintampo north municipality and the Kintampo south district.

In total, 16 qualitative interviews were performed by the research team (Table 1). They consisted of one focused group discussion (FGD) with opinion leaders from the various communities, 4 FGDs with adolescents, 
Table 1. Interview population and types of interviews.

\begin{tabular}{ccccc}
\hline Population & \multicolumn{2}{c}{ In-depth interviews } & \multicolumn{2}{c}{ Focused group discussions } \\
\cline { 2 - 5 } & Target & Done & Target & Done \\
\hline Adolescents & - & - & 4 & 4 \\
Opinion leaders & 10 & 4 & 1 & 1 \\
Health workers & 10 & 7 & - & - \\
Total & $\mathbf{2 0}$ & $\mathbf{1 1}$ & $\mathbf{5}$ & $\mathbf{5}$ \\
\hline
\end{tabular}

4 in-depth interviews (IDIs) with opinion leaders of the communities and 7 IDIs with health workers linked to FP service provision in the communities studied. Each of the 5 FGDs had a minimum of 8 participants. The interviews were recorded using electronic audio devices and backed up with hand-written notes. Interviews were carried out till saturation.

\subsection{Data Analysis}

A team of three researchers transcribed the audio recordings of the FGDs and IDIs. Two members of the research team carried out a thematic analysis of the qualitative data gathered with manual coding. Themes that were identified together with related quotes have been included in this manuscript.

\subsection{Ethical Approval}

The Kintampo Health Research Centre Institutional Ethics Committee (KHRC IEC) approved the study prior to its implementation. As FP research involves inquiring from respondents about their sexual behaviors and practices, a situation that might cause some level of embarrassment to some respondents, precautions were taken by ensuring that the study team educated respondents on sensitive issues envisaged in the questionnaires. Respondents granted interviews only after they had thoroughly understood the content and relevance of the survey; had a chance to ask any questions of interest and received clarifications. It was only after these that they assented/ consented to be part of the study. For adolescents below 18 years of age who assented, their Legally Authorized Representatives (LAR) also consented on their behalf to be part of the study. Data confidentiality was maintained throughout the study, including storing them on computers secured with passwords.

\section{Results}

In all, 54 persons took part in the study; 43 in the 5 focus groups and 11 in the in-depth interviews (Table 2). Of those involved in the study, opinion leaders, healthcare providers and adolescents were all of both genders. The ages of the adult respondents ranged between 31 and 79 years. Adolescent females ranged between 13 and 17 years, whereas their male counterparts were between 13 and 19 years.

The levels of education of adults involved in the study were quite varied; some were with no formal education, others with Middle School Leaving Certificates (MSLC), Junior and Senior High School (JHS/SHS) certificates and some others with diplomas. The adolescent population was at the time of the study Primary 6 to Junior High School students. Study participants were predominantly from the traditional Bono, Mo and Dagarba ethnic groups, with a minority of respondents from migrant ethnic groups within Ghana.

\subsection{Perspectives of Society and Healthcare Providers on FP Care Delivery to Adolescents}

1) Preventing and reducing unwanted teenage pregnancies is a good thing

Views expressed meant that it was good for adolescents to use FP so as to prevent unwanted pregnancies and complications that might arise; as described in the words of a health worker- "It is good we introduce it to them (young people) because the person will not abstain from sexual relationship because he or she is young so once they are already doing it they would have to do family planning to avoid teenage pregnancy. Sometimes a young man impregnates someone and runs away from the community and because the girl does not want anybody to know she is pregnant, she tries all means to terminate the pregnancy and this brings a lot of problems" (male healthcare provider). 
Table 2. Demographic characteristics of study population.

\begin{tabular}{cccc}
\hline Characteristics & Males & Females & Total \\
\hline Age groups & & & 9 \\
13 - 14 years & 6 & 12 & 26 \\
$15-19$ years & 14 & 5 & 19 \\
Above 20 years & 14 & & 2 \\
Level of education & & 0 & 5 \\
No education & 2 & 2 & 40 \\
Primary & 3 & 18 & 7 \\
MSLC/JSS & 22 & 3 & 22 \\
SSS \& beyond & 4 & 10 & 14 \\
Ethnicity & 12 & 6 & 8 \\
Bono & 8 & 2 & 10 \\
Mo & 6 & 5 & \\
Dagarba & 5 & 5 & \\
Others & & & \\
\hline
\end{tabular}

2) FP could help adolescents achieve greater heights

There was the view that FP could facilitate adolescents' achievement of certain life ambitions, such as completing school, learning a trade, to mention a few. An opinion leader was of the view, "That (FP) will help the person to achieve her aim whether you are attending school or learning a trade. Maybe the person does not want to destroy her future; if she does not go for family planning she could get pregnant and that will prevent her from achieving her aim" (female opinion leader).

3) Adolescents experience obstacles in accessing FP services

Participants corroborated various obstacles to adolescents accessing FP services. One is the financial cost of accessing FP services as stated by an opinion leader, "if someone wants to do family planning he may be thinking about the cost, maybe she might not have the money to do it, for family planning you need not to be sick before you do family planning, so I believe if someone really wants to do it she can walk to pick a car and go, because we even walk a long distance to go to market, so I think the distance is not really a problem but then the money is the issue" (male opinion leader). Another obstacle identified is the stigma associated with sexually active adolescents seeking FP and the community's perception that they are bad or spoilt kids. An adolescent described the situation as such, "They (adults) usually see (view) such a (young) person (going for FP) as a prostitute who does not want to give birth, so as to continue his or her prostitution" (male adolescent). An opinion leader described adolescents seeking FP as "A lot of them are not good (spoilt)" (female opinion leader). Adolescents felt that healthcare providers generally do not make it any easier for them to access FP, "When you are a child and you go to the drugs store that you need some of the family planning drugs, they will mistreat you and brand you as a spoilt child" (male adolescent). It is no wonder then that shyness and intimidation creates another barrier to access. Not only do many adolescents lack the confidence to inquire about FP, they feel nervous about the prospect of having to answer a health worker's many questions about their personal circumstances and motives for wanting to use FP. Another obstacle mentioned was, health workers not keeping to rules of confidentiality. One adolescent observed, "Sometimes if you have a boyfriend or a girlfriend that your parents are not aware of and you decide to go and do family planning, the health worker will go and tell your parents" (male adolescent). Some respondents, however, thought that healthcare providers do perform their roles credibly. This view was held by the opinion leaders interviewed, but adolescents interviewed held dissenting views as they had had different experiences as FP clients.

4) FP is not good for adolescents as they could be corrupted by the knowledge and become promiscuous

Educating adolescents about FP was perceived by some respondents as leading them into promiscuity instead of healthy behaviors. A male health worker stated: "as a child, once you have taught him/her he will do it. So, for me, once the fellow is not up to the age... in my opinion, there is no need to teach him those things... For me, it should stop... when you render the education... the demonstrations that you will do... in the course of educat- 
ing, discloses certain things, you see? You see... sometime ago, we went... druggists went for a workshop concerning this very condom. When we went, they had carved a certain stick (laughs) exactly like our manhood and with that, they demonstrated how to wear a condom and after you have finished doing your own thing how you can remove it, you see? So if you go to stand in front of that 10 to 19 year old child to teach this, it will even draw the attention of the child to the thing, you see? So, for me... this kind of education... if the fellow is not up to the age of marriage, let us not teach them things like that..." (male healthcare provider). Despite beliefs about the potential of FP leading adolescents into promiscuity, some respondents recognized the need to promote FP to prevent maternal deaths. Even while condemning FP's role in “corrupting” adolescents, some acknowledged that "protecting the child... to live longer" was more important.

5) There are (perceived) complications of FP use among adolescents

FP was thought to have adverse health effects as described by an adolescent, “... maybe the person might have heard that a colleague had complications due to this family planning for instance may be a swelling of one's buttocks, which has disabled an individual, or some others acquire heart diseases or feel dizzy when they take the injection. So these and some other... things discourage the young ones from engaging in family planning" (female adolescent).

6) Adolescents need to know the various FP methods and the limitations of each

Concerns were expressed by respondents about the misperception that FP affords full protection against STIs for the user. They were concerned that young people were having an erroneous sense of security from STIs for example, once they used a FP method, and as such they need to be educated as much as possible on the various methods and their limitations. A healthcare provider noted "family planning is good but we have to be cautious... We tell them (adolescents) that if they can abstain from sex, then they do not need family planning. The fact that you have done the family planning does not mean you have protected yourself against HIV/AIDS, because family planning is not only condom and the other method does not protect you against other sexually transmitted diseases. So whilst we educate people on family planning, we have to tell them about the STIs... Especially the young girl as soon as they do the family planning they think it is all over; they can do whatever they want" (female healthcare provider).

\subsection{Perspectives from Society, Healthcare Providers and Adolescents on How Best to Address Adolescents' FP Needs}

1) There is the need to educate communities and adolescents on the benefits of FP

Community education was seen by respondents as a means to get them to understand FP and thus reduce teenage pregnancies. A healthcare provider summarized this sentiment.

"We need to talk to them (the school children and the community) and explain to them the benefits of family planning; it is all about talking to them" (female healthcare provider).

2) There is the need to educate communities and adolescents on FP methods and where they can be accessed

Study participants were of the opinion that community members should be educated on FP methods, their availability and accessibility. A male health worker observed, "Family planning drugs are plenty in the system and I have never heard of shortage but for people to understand and do the family planning is a problem. They do not know why they should do the family planning so we have a lot to do. If possible, we should go into the communities, gather people and talk to them about the benefits of doing the family planning, radio announcements and one on one education. The numbers of people who know about it (different family planning methods) are really small and education and publicity is minimal" (male healthcare provider).

3) The state should be committed to FP

Adolescents expressed the need for government to commit to FP programs through infrastructural developments and the enactment of supportive legislation. An opinion leader amplified that observation: "I think it mostly rests on the government, if the government is really serious to help these young ones then it should be able to make the drugs available at less or no cost at all, because somebody might be interested in it but may not have the money to pay, so that is what the government can also do to... help" (male opinion leader).

4) Societal traditions and customs should be revamped/reinstituted to facilitate FP interventions

Some adolescents thought that the reinstitution of traditional values and rites of passage into adulthood could go a long way to enhance FP use among adolescents and reduce unwanted pregnancies-as described by an adolescent: "Kyiribra (puberty rites) if they bring it back it will scare the young ones from getting pregnant so 
they will resort to using family planning" (male adolescent).

5) Religious leaders have a role to play in accepting FP services

It was suggested by Health care providers that religious leaders in the communities should be made to take on roles to create awareness and acceptance of FP. A healthcare provider had the following suggestion, "In our community when we say someone is a leader, the rest of us follow him without challenging him. For example a religion like Islam, if the leaders could talk to their people for them to understand the family planning, they will also tell others about it. It is the leaders who will talk against it but if they don't do that, to their people it means the thing is good. The same can be done for the traditional healers; we should form an association for them so that we can talk to them about family planning" (male healthcare provider). Other study participants were however of the view that religious leaders could not do much to change entrenched beliefs of community members to or not use FP.

6) FP services should be made free of charge and readily accessible

Free and readily accessible FP services were seen by respondents as a facilitator to successful FP programs. In the words of a healthcare provider, "If it is available and then it's free they (adolescents) will go and take it" (female healthcare provider). An opinion leader observed that with maternity services being free of charge and people having to pay for FP services, there was an incentive to have more babies instead of practicing FP.

7) Education is needed to change poor healthcare provider attitudes

An issue raised was the need for healthcare providers to change their approach to adolescents (as FP clients) by addressing them with respect and adhering to the principles of confidentiality.

8) Parents and elders of the community have a role in FP service acceptance of adolescents

Parents' role cannot be underestimated in adolescent's use of FP services, an opinion leader commented, "I think it also depends on the sort of relationship that exists between you and your child, some of the children fear their parents to the extent that they can't discuss family planning matters with them" (male opinion leader). Another opinion leader's comments on how parents' support for their children could enhance their use of the services, "all will depend on the good parenting that we will give to our children, for instance if you have invested expensively in your child's education you would do all that you can and even advise her to do the family planning" (male opinion leader).

\section{Discussion}

Views of respondents on the role of FP in the lives of adolescents were varied. A significant and encouraging finding came from some opinion leaders and healthcare providers who were of the view that FP was good for adolescents as it could prevent unwanted pregnancies and their complications as well as help them achieve their life's objectives. Such opinion leaders and healthcare providers could serve as advocates, enlightening the communities and promoting the acceptance of FP methods to adolescents. Others were however of the conventional view that, adolescents would be corrupted by the knowledge acquired and become promiscuous, this view is supported by publications from some earlier studies on the sub-continent [11]-[13].

Adolescents were found to face some barriers in accessing FP services. These included the cost of services, societal perceptions of adolescents patronizing FP being spoilt [11]-[14], and healthcare providers who were judgmental, discriminatory [7] [15] [16] and did not abide by the principles of privacy and confidentiality [9] [17] during FP service provision to adolescents. Shyness and intimidation tends to be another barrier to access resulting from societal and healthcare provider attitudes [7] [16]. Many adolescents as a result lack the confidence to inquire about FP out of fear of their encounter with a health worker. The fear of perceived complications from FP use [14]-[16] [18] could prevent adolescents from accessing such services. Another relevant finding from this study was cost of services that did come up as a barrier in this study in contrast to an earlier review of experiences of young persons from LMICs [19].

Community awareness of the different types of FP methods was found to be limited in this study. Though some FP programs provide dual protection against unintended pregnancies and HIV/STIs [20], some adolescents in the current study erroneously assumed that FP use may generally protect them against STIs as well. As a preventive measure, adolescents should be well-educated about the diverse forms of contraception, together with their limitations, and provided with information on sources for counseling on dual protection.

Suggestions to address FP needs of the adolescent population included education of healthcare workers on attitudinal change towards adolescent FP clients, a sentiment shared by other adolescents in other sub-Saharan 
African countries [15] [16]. Education was also suggested for community members and adolescents on FP methods, points of access and benefits of their utilization. Some studies that portray poor knowledge of contraceptive methods by adolescents make the case for their need of education [18]. The state's commitment to FP programs to adolescents in the form of available infrastructure, free services and legislations was seen as essential in addressing adolescents' FP needs. Support of religious leaders is crucial to sexual and reproductive health interventions in communities, as illustrated by an experience in Bangladesh [21], where religious leaders literally put an intervention on hold for half a year before restarting it after being appropriately involved.

\section{Limitations}

Participants were purposively sampled from within the studied area, as such their views may not be exactly the views of the larger community members.

\section{Discussion}

\section{Conclusion and Recommendation}

Findings suggest that opinion leaders and healthcare providers see pregnancy prevention through FP as important to the wellbeing and development of adolescents. Study participants also observed that there were factors inhibiting FP utilization by adolescents. They also described as very important the role of opinion leaders including those of religious groupings in facilitating a change in perceptions towards adolescents' use of FP.

Based on the above, recommendations made were as follows:

Community: Opinion leaders and healthcare providers should spearhead efforts at changing negative attitudes to FP and de-stigmatizing its use by adolescents. Parents and community elders should be actively involved in addressing the FP needs of adolescents.

Healthcare providers: FP providers require education on good adolescent client relationships, on how to counsel and attract adolescents who require help in accessing FP services. FP providers should also educate communities and adolescents on FP methods and their limitations, benefits of using them and points where they could be accessed.

Healthcare policy makers/political leadership: Policy makers and political leaders should ensure FP services are free and accessible to all adolescents who need them. They should also provide the right legislative framework to stimulate appropriate infrastructure and resources to enhance FP access to adolescents.

\section{Acknowledgements}

We thank the Management and staff of KHRC for the financial and administrative support for this study. We are grateful to our study participants who took time off their schedules to make this study possible. We appreciate the contribution of the Acting Municipal Director of Health Services, Mad. Alice Vorleto in training of field staff on technicalities related to family planning service delivery ahead of the study. We also acknowledge the support of the entire KHRC Sexual and Reproductive Health (KHRC-SRH) team throughout the course of this study.

\section{Funding Sources}

The funding of this study was mainly from the Kintampo Health and Demographic Surveillance System (KHDSS). MEASURE Evaluation PRC, Chapel Hill, North Carolina partially supported this study with an amount of US \$6000 from USAID Cooperative agreement \# GPO-A-00-09-00003-00 for which we are very grateful.

\section{References}

[1] Ghana Statistical Service (GSS), Ghana Health Service (GHS), ICF Macro (2009) Ghana Demographic and Health Survey 2008. GSS, GHS and ICF Macro, Accra.

[2] World Health Organization [WHO] (2012) Adolescent Pregnancy. Fact Sheet No. 364. May 2012. www.who.int/mediacentre/factsheets/fs364/en/

[3] Enuameh, Y., Boamah, E., Nettey, O.E., Tawiah, C., Manu, A., Sulemana, A., Zandoh, C., Adjei, G., Mahama, E., 
Gyaase, S., Afari-Asiedu, S. and Owusu-Agyei, S. (2012) Improving Family Planning Service Delivery to Adolescents in Ghana: Evidence from Rural Communities in Central Ghana. Measure Evaluation PRH Working Paper Series. WP-12-128. USAID/Measure Evaluation PRH.

[4] Owusu-Agyei, S., Nettey, O.A., Zandoh, C., Abubakari, S., Adda, A., Amenga-Etego, S. and Mbacke, C. (2012) Demographic Patterns and Trends in Central Ghana: Baseline Indication from the Kintampo Health and Demographic Surveillance System. Global Health Action, 15, 19033.

[5] WHO (2003) Preparing for Adulthood: Adolescent Sexual and Reproductive Health. Progress in Reproductive Health Research, 64, 1-2.

[6] Ringheim, K. and Gribble, J. (2010) Improving the Reproductive Health of Sub-Saharan Africa's Youth: A Route to Achieve the Millennium Development Goals. Population Reference Bureau, Washington DC.

[7] United Nations Population Fund [UNFPA] (2005) State of the World Population 2005: The Promise of Equality, Gender Equity, Reproductive Health and the Millennium Development Goals.

[8] ICF Macro (2010) Millennium Development Goals in Ghana: A New Look at Data from the 2008 Ghana Demographic and Health Survey. ICF Macro, Calverton.

[9] Abdul-Rahman, L., Marrone, G. and Johansson, A. (2011) Trends in Contraceptive Use among Female Adolescents in Ghana. African Journal of Reproductive Health, 15, 45.

[10] Boamah, E.A., Asante, K.P., Mahama, E., Manu, G., Ayipah, E.K., Adeniji, E. and Owusu-Agyei, S. (2014) Use of Contraceptives among Adolescents in Kintampo, Ghana: A Cross-Sectional Study. Open Access Journal of Contraception, 5, 7-15. http://dx.doi.org/10.2147/OAJC.S56485

[11] Sekiwunga, R. and Whyte, S.R. (2009) Poor Parenting: Teenagers' Views on Adolescent Pregnancies in Eastern Uganda. African Journal of Reproductive Health, 13, 113-127.

[12] Kohler, P., Manhart, L.E. and Lafferty, W.E. (2008) Abstinence-Only and Comprehensive Sex Education and the Initiation of Sexual Activity and Teen Pregnancy. Journal of Adolescent Health, 42, 344-351. http://dx.doi.org/10.1016/j.jadohealth.2007.08.026

[13] Starkman, N. and Rajani, N. (2002) The Case for Comprehensive Sex Education. AIDS Patient Care and STDs, 16, 313-318. http://dx.doi.org/10.1089/108729102320231144

[14] Chacko, S., Kipp, W., Laing, L. and Kabagambe, G. (2007) Knowledge of and Perceptions about Sexually Transmitted Diseases and Pregnancy: A Qualitative Study among Adolescent Students in Uganda. Journal of Health, Population and Nutrition, 25, 319-327.

[15] Mkhwanazi, N. (2010) Understanding Teenage Pregnancy in a Post-Apartheid South African Township. Culture Health \& Sexuality, 2, 347-358. http://dx.doi.org/10.1080/13691050903491779

[16] Flaherty, A., Kipp, W. and Mehangye, I. (2005) “We Want Someone with a Face of Welcome”: Ugandan Adolescents Articulate Their Family Planning Needs and Priorities. Tropical Doctor, 35, 4-7. http://dx.doi.org/10.1258/0049475053001813

[17] Haller, D.M., Sanci, L.A., Patton, G.C. and Sawyer, S.M. (2007) Toward Youth Friendly Services: A Survey of Young People in Primary Care. Journal of General Internal Medicine, 22, 775-781. http://dx.doi.org/10.1007/s11606-007-0177-5

[18] O’Sullivan, L.F., Cooper-Serber, E., Kubeka, M. and Harrison, A. (2007) Body Concepts: Beliefs about the Body and Efforts to Prevent HIV and Pregnancy among a Sample of Young Adults in South Africa. International Journal of Sexual Health, 19, 69-80. http://dx.doi.org/10.1300/J514v19n02_06

[19] Enuameh, Y., White, S., Adjei, G., Abokyi, L., Owusu-Agyei, S. and Pearson, A. (2012) Perceived Facilitators and Barriers to Interventions Aimed at Reducing Unintended Pregnancy among Adolescents in Low and Middle Income (Developing) Countries: A Systematic Review of Qualitative Evidence. Joanna Briggs Library of Systematic Reviews, 10, 3338-3413.

[20] Adeokun, L., Mantell, J.E., Weiss, E., Delan, G.E., Jagha, T., Olatoregun, J., Udo, D., Akinso, S. and Weiss, E. (2002) Promoting Dual Protection in Family Planning Clinics in Ibadan, Nigeria. International Family Planning Perspectives, 28, 87-95. http://dx.doi.org/10.2307/3088240

[21] Save the Children (2009) Involving Religious Leaders to Promote Adolescent Reproductive and Sexual Health in Bangladesh. Westport, Connecticut. 
Scientific Research Publishing (SCIRP) is one of the largest Open Access journal publishers. It is currently publishing more than 200 open access, online, peer-reviewed journals covering a wide range of academic disciplines. SCIRP serves the worldwide academic communities and contributes to the progress and application of science with its publication.

Other selected journals from SCIRP are listed as below. Submit your manuscript to us via either submit@scirp.org or Online Submission Portal.
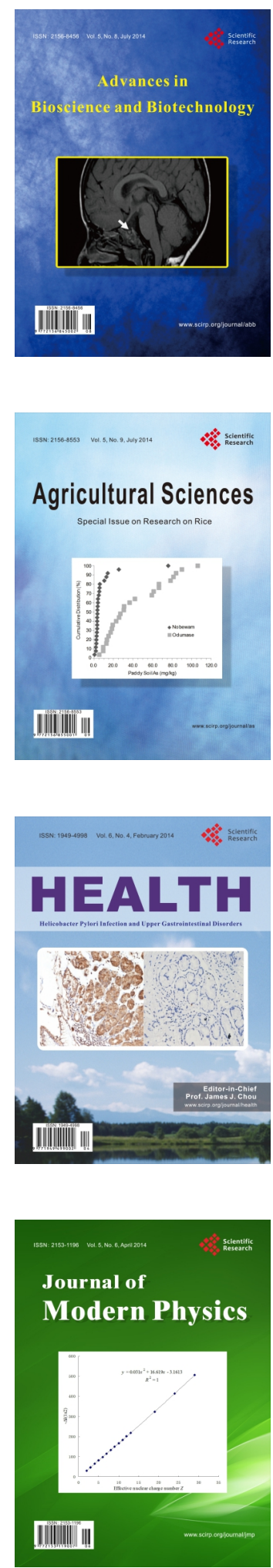
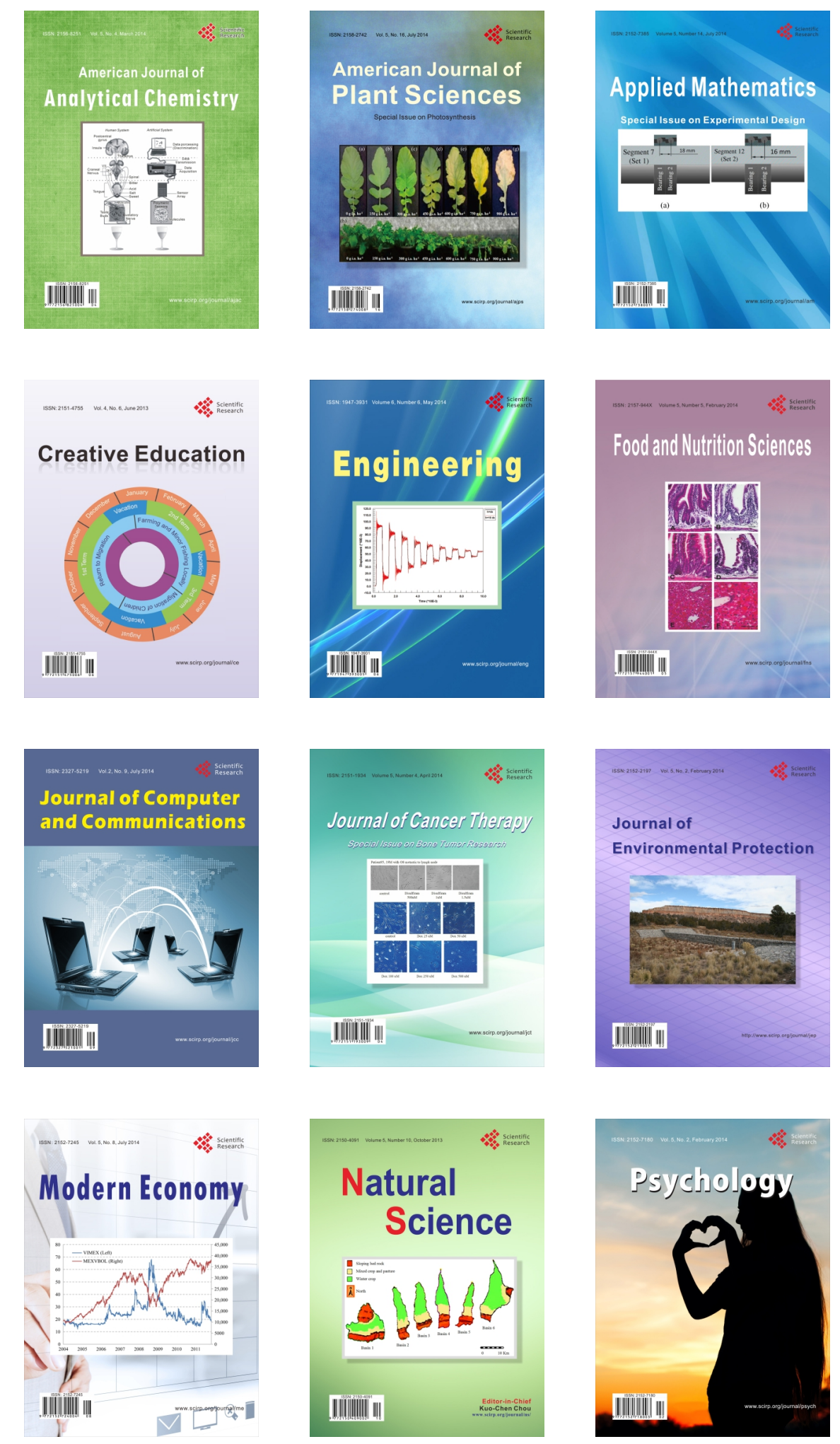